\title{
Takaran Dan Timbangan Yang Adil Dalam Perdagangan Sesuai Al-Quran Surat Hud Ayat 85
}

\author{
Alvi Fauziah \\ Sekolah Tinggi Ilmu Ushuluddin Darul Quran, Bogor \\ Email : fauziahalvi12@gmail.com \\ Putri Khoir Iffah \\ Program Studi Ilmu Al-Qur'an dan Tafsir \\ Sekolah Tinggi Ilmu Ushuluddin Darul Qur'an \\ iffahri79@gmail.com \\ Rachmad Risqy Kurniawan, SEI, MM \\ Sekolah Tinggi Ilmu Ushuluddin Darul Qur'an Mulia, Bogor \\ Email: rah.rizqy@gmail.com
}

\begin{abstract}
This study aims to examine more deeply about justice in trade according to the perspective of Al-Quran Surah Hud verse 85. This study uses the tahlili interpretation method. Based on this research, it can be concluded that Allah SWT has established all laws in this world, one of which is by establishing justice as a law in scales and measures, so that in weighing and measuring in muamalah transactions, especially in trade, one must give rights according to the size. If there is no justice in these measures and scales, it will cause loss and misery in life and create damage in the midst of society as in Surah Hud verse 84.
\end{abstract}

Keywords: Justice, Measure, Scales, Al-Quran

Abstrak: Penelitian ini bertujuan untuk mengkaji lebih dalam mengenai keadilan dalam perdagangan menurut perspektif Al-Quran surat Hud ayat 85. Penelitian ini menggunakan metode penafsiran tahlili. Berdasarkan penelitian ini dapat disimpulkan bahwa Allah SWT telah menetapkan segala hukum di dunia ini, salah satunya dengan menetapkan keadilan sebagai hukum dalam timbangan dan takaran, sehingga dalam menimbang maupun menakar dalam transaksi muamalah khususnya dalam perdagangan harus memberikan hak sesuai dengan ukurannya. Jika keadilan dalam takaran dan timbangan ini tiada, maka akan membuat kerugian dan kesengsaraan hidup serta membuat kerusakan ditengah tengah masyarakat sebagaimana dalam surat Hud ayat 84 .

Keywords : Adil, Takaran, Timbangan, Al-Quran 


\section{Pendahuluan}

Fenomena kecurangan masih banyak terjadi saat ini antara lain masih banyak penjual yang mengurangi timbangan dan takaran, banyak penjual yang tidak jujur dalam memasarkan produknya, semua kecurangan itu akan merugikan pembeli, fenomena ini disebabkan banyak penjual yang belum mengetahui tata cara jual beli yang sesuai dengan syariat Islam karena dalam ajaran agama Islam tidak boleh berlaku curang yang merugikan orang lain karena perbuatan itu termasuk perbuatan dzalim $\mathbf{1}$.

Larangan berbuat curang, merugikan dan berlaku dzalim karena dalam Islam manusia adalah makhluk sosial yang selalu berhubungan dengan makhluk lainnya. Manusia sekaligus sebagai khalifah yang mengemban amanat untuk memakmurkan kehidupan di muka bumi, karena manusia diberikan kedudukan terhormat sebagai mahluk yang paling mulia oleh Allah SWT. Agar kegiatan manusia bernilai ibadah, manusia harus melaksanakan aktivitas hidup dengan menjunjung tinggi ajaran dan nilai-nilai Islam yang terdapat dalam Al-Quran serta petunjuk pelaksanaan yang diberikan oleh Rasulullah SAW didalam sunnahnya.

Al-Quran adalah kitab Allah SWT yang diturunkan kepada Nabi Muhammad SAW sebagai mukjizat yang paling kekal, karena Al-Quran bisa digunakan oleh umat Islam dari zaman dahulu sampai zaman kita sekarang. Al-Quran adalah "hudallinnasi" petunjuk bagi umat manusia, dan menjadi sumber sebagai penguat dalam kehidupan umat Islam. Salah satunya firman Allah SWT mengenai keadilan takaran dan timbangan adalah dalam Surat Hud ayat 85:

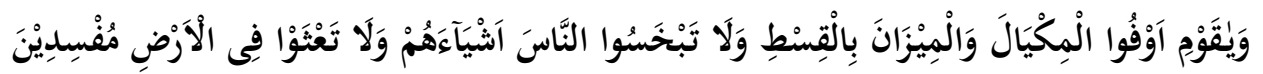

"Dan wahai kaumku! Penuhilah takaran dan timbangan dengan adil, dan janganlah kamu merugikan manusia terhadap hak-hak mereka dan jangan kamu membuat kejahatan di Bumi dengan berbuat kerusakan."

Dari ayat diatas menjelaskan bahwa Allah SWT memerintahkan kita untuk berlaku adil dalam menimbang dan menakar dalam transaksi jual beli. Janganlah kita berbuat licik dengan berlaku curang sehingga merugikan orang lain atau membuat hidup orang lain sengsara.

Kegiatan perdagangan memiliki peran yang sangat vital dalam kehidupan manusia. Sektor perdagangan dianggap cukup menjanjikan dalam meningkatkan kesejahteraan kehidupan manusia. Sektor ini mendatangkan keuntungan yang realtif besar bagi para pelakunya. Hanya saja, kegiatan ini akan mendatangkan permasalahan yang cukup serius jika dilakukan tanpa mengikuti aturan dan norma. Perdagangan yang tujuan dasarnya untuk mencari keuntungan dengan cara dan aturan main yang telah ditetapkan, tetapi sewaktu-waktu dapat diselewengkan oleh pelakunya untuk berbuat curang demi keuntungan lebih ${ }^{2}$.

Dengan melihat kejadian yang terjadi diatas maka penulis akan lebih menelititentang takaran dan timbangansesuai dengan al-Quran yang akan diambil dari beberapa kitab tafsir dan artikel ilmiah terkait penelitian ini. Sehingga penelitian ini

\footnotetext{
${ }^{1}$ Musfira Akbar, Analisis Tingkat Kecurangan Dalam Takaran Dan Timbangan Bagi Pedagang Terigu (Studi Kasus Di Pasar Sentral Maros), FEBI UIN Alauddin Makassar. Jurnal Istisaduna Vol. 2 No. 1 (2016)

${ }^{2}$ Rosalinda, Peranan Pemerintah Dalam Mengawasi Takaran Dan Timbangan: Perspektif Ekonomi Islam, Jurnal Turast: Jurnal Pendidikan dan Pengabdian Vol 2, No 2 (2014).
} 
menjadi dasar pengetahuan dalam keadilan takaran dan penimbangan yang terjadi di masyarakat. Penelitian ini merupakan penelitian kepustakaan (library research) dengan menggunakan literatur (kepustakaan) sebagai sumber antara lain kitab tafsir dan artikel ilmiah lainnya. Metode penafsiran yang digunakan dalam penelitian ini adalahmetode tahlili (analitik) yaitu metode menafsirkan Al-Quran yang berusaha menjelaskan AlQuran dengan menguraikan berbagai seginya dan menjelaskan apa yang dimaksudkan oleh Al-Quran.

\section{Keadilan dalam takaran dan timbangan sesuai Al-Quran}

Dalam Kamus Besar Bahasa Indonesia arti kata keadilan adalah sifat (perbuatan, perlakuan dan sebagainya) yang adil ${ }^{3}$. Keadilan memiliki makna umum dan mempunyai makna khusus, meliputi keadilan dalam bermuamalah, keadilan dalam hukum, keadilan dalam keuangan, dan keadilan dalam hak-hak manusia. ${ }^{4}$

Berbicara tentang keadilan, hal ini tentu saja menjadi hak setiap manusia. Namun nihilnya di negara kita pun belum terealisasikan. Sehingga banyak terjadi hal yang tidak diinginkan. Begitupula dalam perekonomian yang sangat berpengaruh dalam aktivitas kehidupan. Terutama dalam hal perdagangan yang tak akan pernah punah.

Mengenai perdagangan, tentu saja Islam mengajarkan setiap muslim dalam melakukan kegiatan produksi maupun perdagangan untuk bersikap jujur dan adil terhadap sesama, agar tidak ada pihak yang dirugikan. Sikap ini akan tertanam dengan adanya keharusan untuk memenuhi takaran dan timbangan. ${ }^{5}$ Prinsip dasar perdagangan menurut Islam adalah adanya unsur kebebasan dalam melakukan transaksi tukar menukar, tetapi kegiatan tersebut tetap disertai dengan harapan diperolehnya keridhaan Allah SWT. Dan melarang terjadinya pemaksaan. Tidak diperbolehkan adanya permintaan atau meminta ganti rugi dari pihak yang bersangkutan, sebab Rasulullah Saw telah memberikan alternatif dari pihak yang bersangkutan, yaitu dengan merusak jual beli atau menolaknya. ${ }^{6}$

Kunci kesuksesan Rasulullah dalam perdagangan adalah sifat jujur dan adil. Nabi Muhammad SAW. menjadi suri teladan dalam semua aspek kehidupan termasuk dalam aktivitas bisnis. Nabi Muhammad sebagai seorang pedagang, memberikan contoh yang sangat baik dalam setiap transaksi bisnisnya. Beliau melakukan transaksitransaksi secara jujur, adil, dan tidak pernah membuat pelangga mengeluh apalagi kecewa. Beliau selalu menepati janji dan mengantarkan barang dagangannya dengan standar kualitas sesuai dengan permintaan pelanggan.

Lebih dari itu, Nabi Muhammad SAW. juga meletakan prinsip-prinsip dasar dalam melakukan transaksi dagang secara adil. Kejujuran dan keterbukaan Nabi Muhammad dalam melakukan transaksi perdagangan merupakan teladan abadi bagi pengusaha generasi selanjutnya. ${ }^{7}$ Bahkan dalam al-Quran sudah disebutkan bahwa, kita

${ }^{3}$ Badan Pengembangan dan Pembinaan Bahasa Kementerian Pendidikan dan Kebudayaan Republik Indonesia, Kamus Besar Bahasa Indonesia Edisi Kelima, Jakarta: Balai Pustaka, 2017

${ }^{4}$ Muhammad Dhiaduddin Rais, Teori Politik Islam, (Jakarta: Gema Insani Press, 2001), Cet. I, h. 268

${ }^{5}$ Rosalinda, Peranan Pemerintah Dalam Mengawasi Takaran Dan Timbangan: Perspektif Ekonomi Islam, Jurnal Turast: Jurnal Pendidikan dan Pengabdian Vol 2, No 2 (2014).

${ }^{6}$ Taqyuddin Naham, Membangun Sistem Ekonomi Alternatif Islam (Cet I: Surabaya; Risalah Gusti, 1996), h 204205

${ }^{7}$ Herman Kartajaya dan Muhammad Syakir Sula, Syariah Marketing (Bandung: PT. Mizan Pustaka, 2006), 43-44 
harus menyempurnakan takaran dan timbangan secara adil. Hal ini banyak disebutkan dalam al-Quran salah satunya firman Allah SWT yang berbunyi :

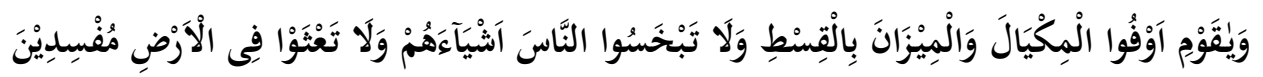

"Dan wahai kaumku! Penuhilah takaran dan timbangan dengan adil, dan janganlah kamu merugikan manusia terhadap hak-hak mereka dan jangan kamu membuat kejahatan di Bumi dengan berbuat kerusakan.",

Imam Ibnu Katsir menjelaskan didalam kitab nya Tafsir Ibnu Katsir bahwa Nabi Syu'aib melarang mereka agar tidak mengurangi timbangan dan takaran, ketika menimbang atau menakar untuk orang lain. Kemudian ia memerintahkakn mereka agar menepati timbangan dan takaran secara adil ( jujur) baik menerima atau memberi. Nabi Syu'aib juga melarang mereka agar tidak berbuat congkak dibumi dengan melakukan kerusakan, karena pada waktu itu mereka sering menjanggal ( merampok ).

Firman Allah SWT بقية الله خير لكم "sisa ( keuntungan) dari Allah SWT adalah lebih baik bagimu." Ibnu Abbas berkata, "yakni rezeki Allah SWT lebih baik dari kalian."Al-Hasan berkata, " sesungguhnya rezeki Allah SWT kepada kalian lebih baik daripada kalian menipu oranga lain." Abdurrahman bin zaid bin Aslam berkata,“ kerugian itu berada disiksa dan keuntungan berada dirahmat." Abu Ja'far bin Jarir berkata tentang ayat بقية الله خير لكم "sisa ( keuntungan) dari Allah SWT adalah lebih baik bagimu." Beliau berkata, "yakni keuntungan yang kalian dapatkan ketika menepati timbangan dan takaran (jujur) itu lebih baik bagi kalian daripada mendapatkan kuntungan akan tetapi dengan berlaku curang."

Ibnu jarir berkata, " keterangan ini diriwayatkan dari Ibnu Abbas.” Saya berkata, " ia serupa dengan firman Allah SWT yang berbunyi,

$$
\text { قل لايستوى الخبيث والطيب ولو أعجبك كثرة الخبيث }
$$

"Tidak sama yang buruk dengan yang baik, meskipun banyaknya yang buruk itu menarik hatimu,...” (Q.S Al-Maidah (5): 100 ).

Dalam Kitab Tafsir at-Thabari, Abu Jafar berkata bahwa Allah SWT. berfirman mengingatkannya atas apa yang dikatakan oleh Syu'aib kepada kaumnya, wahai manusia! cukupkanlah takaran dan timbangan bilqisthi "dengan adil" dan yang demikian itu maka kalian harus mencukupkan hak-hak diantara mereka sesuai dengan takaran dan timbangan atas apa yang telah diwajibkan bagi mereka dari kesempurnaan itu dengan tanpa mengurangi atau melebihi. ${ }^{9}$

Firman Allah SWT. ولا تبخسوا الناس أشياءهم Dan janganlah kalian mengurangi hak-hak mereka yang menjadi kewajiban bagi mereka maka cukupkanlah timbangan atau takaran atau yang lainnya sebagaimana dijelaskan dalam hadits :

\footnotetext{
${ }^{8}$ Q.S Hud : 85

9 Al-Ṭhabarī, Abu Ja ${ }^{e e}$ far Muḥammad Ibn Jarīr Ibn Yazīd Ibn Kathir Ibn Gālib . Jāmi’u al-Bayān fì Ta`wīli al-Qur`ān (Beirut: Daarul Kitab, 1412 H/1992 M)
} 
Seseorang berkata kepada kita, Yazid berkata kepada kita, Sa'id berkata kepada kita, tentang Qatadah : ولا تبخسوا الناس أشياءهم Dia berkata : janganlah mendzalimi hakhak manusia.

Dalam Tafsir al-Misbah ayat di atas merupakan perintah berlaku adil, baik dengan Allah SWT. maupun dengan manusia. Adil pada manusia menurut beliau adalah dengan cara menyempurnakan timbangan saat bermuamalah. Dengan bersikap adil dan jujur saat menimbang lebih baik daripada hasil sebanyak apa pun yang diperoleh melalui penganiayaan dan kecurangan. ${ }^{\mathbf{1 0}}$ Al-qisth pada ayat ini biasa diartikan adil, yaitu sinonim dari $a l$ - ' $d l u$ atau adil. Memang, banyak ulama yang mempersamakan maknanya dan ada juga yang membedakannya dengan berkata bahwa al-qisth berlaku adil antara dua orang atau lebih, keadilan yang menjadikan masing-masing senang. Sedang al-adlu adalah berlaku baik terhadap orang lain maupun diri sendiri tapi keadilan itu bisa saja tidak menyenangkan salah satu pihak. Timbangan dan takaran harus menyenangkan kedua belah pihak. Karena itu, disini digunakan kata bi al-qisth. Muhammad Yusuf Qardhawi menambahkan, bahwa ayat ini anjuran setiap muslim harus bersikap adil dalam setiap transaksi muamalah dalam kehidupan dan pergaulan. ${ }^{11}$

Untuk meminimalisir kecurangan, maka anjurannya yaitu melebihkan timbangan. Sebagaimana menurut Sayyid Sabiq dalam buku Fiqh Sunnah, disunnahkan untuk melebihkan timbangan kepada pembeli dalam menimbang atau menakar. ${ }^{\mathbf{1 2}}$ Sebagaimana hadis dari Suwaid bin Qais dalam Kitab Sunan Ibnu Majah yang artinya : Dari Suwaid bin Qais, ia berkata: Aku dan makhrafah al-Abdi mengambil pakaian dari Hajar, kemudian Rasulullah SAW datang kepada kami dengan berjalan. Beliau menawar sebuah celana, lalu kami menjualnya kepada beliau. Dan di sana ada seorang lelaki yang menimbang dengan mendapatkan upah atau bayaran. Rasulullah SAW .berkata kepadanya, “ Timbanglah dan lebihkanlah."13

Iو وَيََوْمِ اَوْفُوا الْمِكْيَالَ وَالْمِيْزَانَ بِالْقِسنطِ wahai kaum! Sempurnakanlah takaran dan timbangan dengan adil janganlah melebihkan atau menguranginya. Allah SWT SAW telah memerintahkan kepada kalian dengan kewajiban berlaku adil terhadap takaran dan timbangan, Dia telah melarang kalian untuk berbuat licik atau berbuat tidak adil dalam takaran dan timbangan. Hal ini hanya untuk menguatkan pelarangan tersebut, dan menjadi perhatian terhadap ketidaksengajaan dalam mengurangi. Maka tidak cukup untuk menyelidiki kebenaran ini, akan tetapi diwajibkan baginya untuk mengembalikan kepada keadilan dan keseimbangan, tanpa mengurangi dan melebihi.

tabkhosuu “Mengurangi dalam segala hal” dikatakan

bahwa mengurangi hartanya dan mengurangi ilmu serta keutamaannya atau janganlah menzalimi manusia terhadap segala sesuatunya, Demikian itu mencakup untuk 1 orang atau untuk semuanya dalam perihal timbangan, takaran, hitungan, dan batasan dengan perhitungan yang tersirat dan hak-hak yang bersifat material maupun tidak material.

\footnotetext{
${ }^{10}$ Departemen Agama RI, Al-Qur'an dan Terjemahannya (Bandung: Diponegoro,2005), h .231.

11 Yusuf Qardhawi, Halal dan Haram dalam Islam, Terjemahan oleh Mu'amal Hamidy, (Surabaya: Bina Ilmu, 2003),h.365.

${ }^{12}$ Sayyid Sabiq, Fiqh Sunnah Jilid XIII (Bandung: Al-Ma'aruf, 1987), h. 74.

${ }^{13}$ Muhammad Bin Yazid Abu Abdullah Al-Qazwaniy, Sunan Ibnu Majah Jilid 1(Beirut: Dar Al-fikr, 2004), h. 20.
} 
Ajaran Islam memang berorientasi pada terciptanya karakter manusia yang memiliki sikap dan perilaku yang seimbang dan adil dalam konteks hubungan antara manusia dengan diri sendiri, dengan orang lain (masyarakat) dan dengan lingkugan. ${ }^{14}$ Keseimbangan adalah menggambarkan dimensi horizontal ajaran Islam, dan berhubungan dengan harmoni segala sesuatu di alam semesta. ${ }^{15}$ Sebagaimana firman Allah SWT :

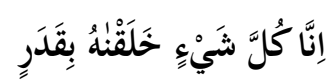

"Sungguh, Kami menciptakan segala sesuatu menurut ukuran." 16

Firman diatas bahwa Allah SWT telah menciptakan segala sesuatu menurut ukuran yang telah tertulis di lauhil mahfudz ${ }^{17}$

Dijelaskan oleh imam Muhammad Ali Ashobuni didalam kitabnya, Sesungguhnya segala yang telah diciptakan di dunia ini itu sesuai dengan kekuasaan Allah SWT dan yang dijadikan di bumi ini sesuai dengan hikmah dan aturan yang sempurna dan sesuai bentuk yang diciptakannya. Sebagaimana firman Allah SWT

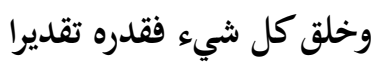

"dan dia telah menciptakan segala sesuatu",18

Dalam kitab tafsir al-Baydhowiy mengenai surat Hud ayat 85, wahai kaum! penuhilah takaran dan timbangan yang telah menjelaskan untuk memenuhi perintah setelah larangan itu atau melebih-lebihkan timbangan, dan ini menjadi perhatian bahwasesungguhnya Allah SWT tidak mencukupkan kepada mereka yang berbuat dengan sengaja itu mendapatkan keringanan. Tetapi dibolehkan bagi mereka memenuhi usaha mereka walaupun dengan menambahkan takarannya, itudibolehkan tapi Allah SWT tidak memerintaknannya, dan itu menjadi pelanggaran hukum.

Kولال تَبْخَسُوا النَّاسَ أَثْيْيَهَهُمْ Kalimat itu adalah kalimat yang umum setelah dikhususkan karena itu lebih umum dari apa yang telah ditentukan atau dalam hal yang lain sebagaimana yang dikatakan firman Allah SWT wala ta'tsau fil ardhi mufsidin dan kalimat ini adalah kalimat umum yang mengurangi hak hak dan yang lainnya dari macam-macam kerusakan. Dikatakan maksudnya seperti menemukan maling dan memotong jalan dan dan kaidah keadaan ini itu mengeluarkan apa yang dimaksud dengan perbaikan, sebagaimana yang dilakukan oleh Khodiro a.s dikatakan maknanya wala ta 'tsau fil ardhi mufsidin maksudnya brbuat kerusakan untuk kebaikan akhirat. ${ }^{19}$

Ada beberapa sifat yang Rasulullah contohkan dalam hal bisnis salahsatunya adalah sifat keadilan, berbisnislah kalian secara adil, Allah SWT berfirman : "Berusahalah secara adil dan kamu tidak boleh bertindak dengan tidak adil" ini adalah salah satu akhlak yang harus dimiliki seorang marketer. Berbisnis secara adil adalah wajib hukumnya bukan hanya imbauan dari Allah SWT. Sikap adil termasuk

\footnotetext{
${ }^{14}$ Mardhiyah Hayati, Investasi dalam Perspektif Bisnis Syariah Kajian Terhadap Uu No. 21 Tahun 2008 Tentang Perbankan Syariah, Al-'Adalah Vol. XII, No. 1 Juni 2014

${ }^{15}$ Muhammad, Etika Bisnis Islam, Yogyakarta: UPP AMP YKPN, 2004

16 Q.S al-Qomar : 49

${ }^{17}$ Syeikh Muhammad Ali As-Shobuni, shofwatuttafasiir jil. III hal. 1252

18 Al-Furqon : 2

${ }^{19}$ Nasiruddiin Abu Sa'id Abdullah, anwa'ut Tanzil wa Asrarut Ta'wil (Beyrut 1-1418H)
} 
diantara nilai - nilai yang telah ditetapkan dalam Islam dalam semua aspek ekonomi Islam. Allah SWT mencintai orang-orang yang berbuat adil dan membenci orang-orang yang berbuat zalim, bahkan melaknat mereka. Firman-Nya "Ingatlah, kutukan Allah SWT (ditimpakan) atas orang-orang yang zalim" (QS Hud (11):ayat 8).Islam telah mengharamkan setiap hubungan bisnis yang mengandung kezaliman dan mewajibkan terpenuhinya keadilan yang teraplikasikan dalam setiap hubungan dagang dan kontrakkontrak bisnis. ${ }^{20}$

Dalam beraktivitas di dunia kerja dan bisnis, Islam mengharuskan untuk berbuat adil, tak terkecuali pada pihak yang tidak disukai. Hal ini sesuai dengan firman Allah SWT

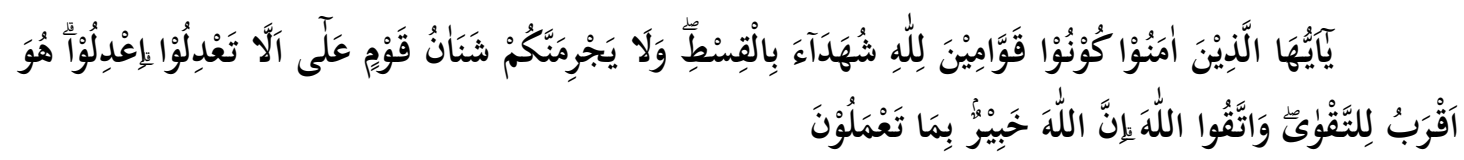

"Wahai orang-orang yang beriman! Jadilah kamu sebagai penegak keadilan karena Allah SWT (ketika) menjadi saksi dengan adil. Dan janganlah kebencianmu terhadap suatu kaum mendorong kamu untuk berlaku tidak adil. Berlaku adillah. Karena (adil) itu lebih dekat kepada takwa. Dan bertakwalah kepada Allah SWT, sungguh, Allah SWT Mahateliti terhadap apa yang kamu kerjakan."21

Azab dan kehinaan yang besar pada hari kiamat disediakan bagi orang-orang yang curang dalam menakar dan menabung. Allah SWT telah menyampaikan ancaman yang pedas kepada orang-orang yang curang dalam menakar dan menimbang yang terjadi di tempat-tempat jual beli di Mekah dan Madinah pada waktu itu.

Diriwayatkan bahwa di Madinah ada seorang laki-laki bernama Abu Juhainah. Ia mempunyai dua macam takaran yang besar dan yang kecil. Bila ia membeli gandum atau kurma dari para petani ia mempergunakan takaran yang besar, akan tetapi jika ia menjual kepada orang lain ia mempergunakan takaran yang kecil. Perbuatan seperti itu menunjukan adanya sifat tamak, ingin mencari keuntungn bagi dirinya sendiri walaupun dengan jalan merugikan kepada orang lain. ${ }^{22}$

Terhadap orang seperti itu Nabi Muhammad SAW. telah memberi ancaman yang kuat sekali seperti dalam hadits Rasulullah yang artinya, "ada lima perkara yang dibalas dengan lima perkara: tidak pernah suatu kaum yang melanggar janji, melainkan Allah SWT akan membiarkan kaum itu dikuasai musuhnya. Tidak pernah mereka yang memutuskan perkara dengan hukuman yang tidak diturunkan oleh Allah SWT, melainkan akan tersebar luaslah kefakiran dikalangan mereka. Perzinaan tidak pernah secara meluas dikalangan mereka secara luas, melainkan akan tersebar luaslah bahaya kematian. Tidak pernah mereka yang berbuat curang dalam menakar dan menimbang, melainkan mereka akan kehilangan kesuburan tumbuh-tumbuhan dan ditimpa musim kemarau. Dan tidak pernah mereka yang menahan zakat, melainkan akan diazab dengan hujan (kemarau yang panjang). (Riwayat at-Tabrani dari Ibnu 'Abbas) $)^{\mathbf{2 3}}$

\footnotetext{
${ }^{20}$ Nashruddin Baidan dan Erwati Aziz, Etika Islam dalam Berbisnis ( Solo: Zada Haniva, 2008) 72-73

${ }^{21}$ Q.S. Al-Maidah : 8

${ }^{22}$ Hafizh Dasuki, M.A., dkk, Al-Qur'an Dan Tafsirnya, Jilid 1, PT. Dana. Bhakti Wakaf, Yogyakarta, 1990

${ }^{23}$ Hafizh Dasuki, M.A., dkk, Al-Qur'an Dan Tafsirnya, Jilid 1, PT. Dana. Bhakti Wakaf, Yogyakarta, 1990
} 
Imam Jalaluddin dan al-Mahalli dan Imam Jalaluddin as-Suyuthi menjelaskan dalam kitab tasfirnya : "(Dan Syuaib berkata, "Hai kaumku!) (Cukupkanlah takaran dan timbungan) sempurnakanlah keduanya (dengan adil) secara tetap (dan janganlah kalian merugikan manusia terhadap hak-hak mereka) janganlah kalian mengurangi hak-hak mereka sedikit pun (dan janganlah kalian membuat kejahatan di muka bumi dengan membuat kerusakan) dengan melakukan pembunuhan dan kejahatan lainnya. Lafal ta'tsau berasal dari fi'il madhi `atsiya, artinya mengadakan kerusakan. Sedangkan lafal mufsidiina berkedudukan menjadi hal atau keterangan yang mengukuhkan makna amilnya yaitu ta'tsau."

Keseimbangan atau keadilan menggambarkan dimensi horizontal ajaran Islam yang berhubungan dengan keseluruhan harmoni pada alam semesta. Hukum dan tatanan yang kita lihat pada alam semesta mencerminkan keseimbangan yang harmonis. (Beekun, 1997: 23.) Dengan demikian keseimbangan, kebersamaan, kemoderatan merupakan prinsip etis mendasar yang harus diterapkan dalam aktivitas maupun entitas bisnis. $^{24}$

\section{Penutup}

Berdasarkan kesimpulan diatas bahwa, Allah SWT telah menetapkan segala hukum di dunia ini, salah satunya dengan menetapkan keadilan sebagai hukum dalam timbangan dan takaran, sehingga dalam menimbang maupun menakar dalam transaksi muamalah khususnya dalam perdagangan harus memberikan hak sesuai dengan ukurannya. Jika keadilan dalam takaran dan timbangan ini tiada, maka akan membuat kerugian dan kesengsaraan hidup serta membuat kerusakan ditengah tengah masyarakat sebagaimana dalam surat Hud ayat 84 .

\section{Daftar Pustaka}

Al-Ṭhabarī, Abu Jaeefar Muhammad Ibn Jarīr Ibn Yazīd Ibn Kathir Ibn Gālib . Jāmi’u al-Bayān fì Ta`wīli al-Qur’ān (Beirut: Daarul Kitab, 1412 H/1992 M)

Badan Pengembangan dan Pembinaan Bahasa Kementerian Pendidikan dan Kebudayaan Republik Indonesia, Kamus Besar Bahasa Indonesia Edisi Kelima, Jakarta: Balai Pustaka, 2017

Departemen Agama RI, Al-Qur'an dan Terjemahannya (Bandung: Diponegoro, 2005), h .231.

Hafizh Dasuki, M.A., dkk, Al-Qur'an Dan Tafsirnya, Jilid 1, PT. Dana. Bhakti Wakaf, Yogyakarta, 1990

Kartajaya, Herman dan Sula, Muhammad Syakir,. Syariah Marketing (Bandung: PT. Mizan Pustaka, 2006), 43-44

Hidayatullah, Haris. Etika Bisnis Dalam Prespektif Al-Quran: Upaya Membangun Bisnis Yang Islami Untuk Menghadapi Bisnis Di Masa Depan, Fakultas Agama Islam Unipdu Jombang.

\footnotetext{
${ }^{24}$ Hidayatullah, Haris. Etika Bisnis dalam Prespektif Al-Quran: Upaya membangun bisnis yang Islami untuk menghadapi bisnis di masa depan, Fakultas Agama Islam Unipdu Jombang. 
Hayati, Mardhiyah, Investasi dalam Perspektif Bisnis Syariah Kajian Terhadap Uu No. 21 Tahun 2008 Tentang Perbankan Syariah, Al-‘Adalah Vol. XII, No. 1 Juni 2014

Al-Qazwaniy, Muhammad Bin Yazid Abu Abdullah, Sunan Ibnu Majah Jilid 1(Beirut: Dar Al-fikr, 2004), h. 20.

Muhammad Dhiaduddin Rais, Teori Politik Islam, (Jakarta: Gema Insani Press, 2001), Cet. I, h. 268

Muhammad, Etika Bisnis Islam, Yogyakarta: UPP AMP YKPN, 2004

Musfira Akbar, Analisis Tingkat Kecurangan Dalam Takaran Dan Timbangan Bagi Pedagang Terigu (Studi Kasus Di Pasar Sentral Maros), FEBI UIN Alauddin Makassar. Jurnal Istisaduna Vol. 2 No. 1 (2016)

Nashruddin Baidan dan Erwati Aziz, Etika Islam dalam Berbisnis ( Solo: Zada Haniva, 2008) $72-73$

Nasiruddiin Abu Sa'id Abdullah, Anwa'ut Tanzil wa Asrarut Ta'wil (Beyrut 1-1418H)

Rosalinda, Peranan Pemerintah Dalam Mengawasi Takaran Dan Timbangan: Perspektif Ekonomi Islam, Jurnal Turast: Jurnal Pendidikan dan Pengabdian Vol 2, No 2 (2014).

Sayyid Sabiq, Fiqh Sunnah Jilid XIII (Bandung: Al-Ma'aruf, 1987), h. 74.

Syeikh Muhammad Ali As-Shobuni, Shofwatuttafasiir jil. III hal. 1252

Taqyuddin Naham, Membangun Sistem Ekonomi Alternatif Islam (Cet I: Surabaya; Risalah Gusti, 1996), h 204205

Yusuf Qardhawi, Halal dan Haram dalam Islam, Terjemahan oleh Mu'amal Hamidy, (Surabaya: Bina Ilmu, 2003),h.365. 